\title{
Extraction and antioxidant activity of phenolic compounds from wheat bran treated by steam explosion
}

\author{
Xueling Zheng, Ruiting Zhang and Chong Liu* \\ College of Grain and Food, Henan University of Technology, Zhengzhou, 450001, PR China \\ *For correspondence: Email: liuachong@126.com
}

Received: 15 May 2015

Revised accepted: 9 September 2015

\begin{abstract}
Purpose: To use response surface methodology to optimize the extraction of the phenolic compounds in wheat bran treated by steam explosion, and to determine the antioxidant activity of the extract obtained.

Methods: By using response surface methodology, the effects of extraction time, methanol concentration, liquid/solid and temperature were studied and optimized. 2,2-Diphenyl-1-(2,4,6trinitrophenyl) hydrazyl (DPPH) radical-scavenging capacity, reducing capacity and 2,2'-Azino-bis(3ethylbenzothiazoline-6-sulfonic acid) diammonium salt (ABTS) radical scavenging capacity were also employed to determine antioxidant activity of the extract.

Results: Under the optimal conditions, i.e., extraction time: 120 s, ethanol content: $43 \%$, liquid/solid: 35:1, temperature: $70^{\circ} \mathrm{C}$, the experimental total phenolic yield was $30.464 \pm 0.025$, which agreed with the predicted value of 31.687. The phenolic compounds showed strong antioxidant activities. At extract concentration of $1 \mathrm{mg} / \mathrm{ml}$, DPPH radical-scavenging activity was $50 \%$. Although its reducing power (2 $10 \mathrm{mg} / \mathrm{mL}$ ) was lower than that of BHA, ABTS radical scavenging of the extract (close to $90 \%$ ) was higher than that of BHA at extract concentration $>6 \mathrm{mg} / \mathrm{mL}$.

Conclusion: The yield of the phenolic compounds was high and the compounds displayed strong antioxidant capacity, which indicates that the extraction of wheat bran under steam explosion holds high potentials for the food and pharmaceutical industries.
\end{abstract}

Keywords: Wheat bran, Steam explosion, Extraction, Response surface methodology, Antioxidant capacity

Tropical Journal of Pharmaceutical Research is indexed by Science Citation Index (SciSearch), Scopus, International Pharmaceutical Abstract, Chemical Abstracts, Embase, Index Copernicus, EBSCO, African Index Medicus, JournalSeek, Journal Citation Reports/Science Edition, Directory of Open Access Journals (DOAJ), African Journal Online, Bioline International, Open-J-Gate and Pharmacy Abstracts

\section{INTRODUCTION}

Wheat bran is one of the main by-products of the wheat-milling industry. Wheat bran fiber contains many antioxidants, these substances are mainly phenolic compounds, total amount can be as high as $500 \mathrm{mg} / \mathrm{kg}$ [1]. The wheat phenolic compounds are mainly phenolic acids, flavonoids and lignans. Ferulic acid was the dominant phenolic acid in wheat bran which accounted for $59-60 \%$ of the total phenolic acids on a per weight basis [3]; it is an excellent free radical scavenger and has the antioxidant capacity [1].

Steam explosion is beneficial for the release of cellulose and hemicelluloses, because of the combination between phenolic acids and cellulose. Therefore, steam explosion treatment is also beneficial for the release of phenolic acids.

This study employed central composite design (CCD) to optimize its extraction, and determine 
the antioxidant activity of the obtained extraction [6].

\section{EXPERIMENTAL}

\section{Materials}

Commercial wheat bran (XinLiang Flour Company), 2,2-Dipheny-I-picrylhydrazyl (DPPH), ABTS, Folin-Ciocalteu phenol reagent, $\mathrm{Na}_{2} \mathrm{CO}_{3}$ solution, gallic acid, potassium ferricyanide, trichloroacetic acid (TCA), disodium hydrogen phosphate, sodium dihydrogen phosphate, ferric chloride, potassium persulphate.

\section{Extraction methods}

According to the previous study [11], the steam explosion treatment for the wheat bran was done under the following conditions: pressure ( $\mathrm{MPa})$ : 2.5, time: $30 \mathrm{~s}$, and $\mathrm{T}\left({ }^{\circ} \mathrm{C}\right): 224$.

The sample of $1 \mathrm{~g}$ of the wheat bran with the treatment of steam explosion above was placed in a flask and extracted with ethanol at a different concentration, different temperature, different liquid/solid ratio, and extraction time, then filtered under a vacuum. The filtrate was diluted to 100 $\mathrm{mL}$ for determining the total phenolic content.

\section{Determination of total phenolic yield}

The total phenolic content was determined according to the Folin-Ciocalteu method [6]. Briefly, $300 \mu \mathrm{L}$ of untreated and treated wheat bran extract solution was added to a $25 \mathrm{~mL}$ volumetric flask, and additional $\mathrm{H}_{2} \mathrm{O}$ was added to make a final volume of $10 \mathrm{~mL}$. A reagent blank was prepared using $\mathrm{H}_{2} \mathrm{O}$. Folin-Ciocalteu phenol reagent $(0.5 \mathrm{~mL})$ was added to the mixture, than shaken vigorously. After $5 \mathrm{~min}, 5 \mathrm{~mL}$ of $5 \%$ $\mathrm{Na}_{2} \mathrm{CO}_{3}$ solution was added with mixing. Distilled water was added immediately to make a final volume of $25 \mathrm{~mL}$ and mixed thoroughly. The solution was allowed to stand for $90 \mathrm{~min}$. Then, the absorbance was read at $750 \mathrm{~nm}$. The total phenolic content of extract solution was measured as gallic acid equivalents [2].

\section{Experimental design}

Response surface methodology (RSM) with appropriate experimental designs, e.g., central composite design (CCD), is a method based on mathematical statistics theory, which has been widely used to optimize the intended parameters in the extraction and modification of bioactive compounds in grain and oil food, chemistry and other aspects [6,9]. Response surface methodology was used to optimize experimental conditions for extraction of total phenolic yields from wheat bran samples.

In this design, four factors including extraction time (A) methanol concentration (B), liquid/solid ratio (C), and temperature (D) were selected as independent variables in CCD. This three-level, four-factor, central composite design (CCD) was employed, in which 30 experiments were involved, and the total phenolic yields $(\mathrm{Y})$ was used as response in evaluating the extraction.

The star points were added to the factorial design to provide for estimation of curvature of the model. Six replicates (No. 25, 26, 27, 28, 29, and 30 ) at the center of the design were used to allow for estimation of "pure error" sum of squares. Experiments were randomized in order to minimize the effects of unexplained variability in the observed response due to extraneous factors.

\section{Preparation of wheat bran}

The sample under optimal treatment was used to test the antioxidant capacity. The BHA was tested as the control group.

3(2)-tert-Butyl-4-hydroxyanisole (BHA) is a manmade compound, which is a good kind of antioxidant, with no toxicity under the proper concentration. As a food antioxidant, BHA can hinder the oxidation of the grease food and delay the time of becoming corrupt.

Table 1: Factors and levels of response surface methodology

\begin{tabular}{lllll}
\hline Level & $\begin{array}{l}\text { A } \\
\text { Extraction time } \\
(\mathbf{m i n})\end{array}$ & $\begin{array}{l}\text { B } \\
\text { Ethanol concentration } \\
(\%)\end{array}$ & $\begin{array}{l}\text { C } \\
\text { Liquid/solid } \\
\text { ratio }\end{array}$ & $\begin{array}{l}\text { D } \\
\text { Temperature } \\
\left({ }^{\circ} \mathrm{C}\right)\end{array}$ \\
\hline-1 & 40 & 40 & 20 & 30 \\
0 & 80 & 60 & 30 & 50 \\
1 & 120 & 80 & 40 & 70 \\
\hline
\end{tabular}




\section{DPPH radical scavenging assay}

The DPPH radical scavenging assay was determined according to the published method $[4,7,10]$ with some modification. Briefly, $2 \mathrm{~mL} 0.2$ $\mathrm{mM}$ of DPPH solution (dissolved in ethanol) was mixed with $2 \mathrm{~mL}$ of the extract solution. The solution mixture was shaken vigorously and was incubated for $30 \mathrm{~min}$ in the dark at room temperature. After that, the absorbance was read spectrophotometrically at $517 \mathrm{~nm}$ against ethanol. Control was ethanol instead of the antioxidant solution, and reagent blank was ethanol instead of DPPH solution. The inhibition of DPPH radical by the sample was calculated as in $\mathrm{Eq} 1$.

Inhibition $(\%)=\{(A c-A s) / A c\} 100$

where Ac and As are the absorbance of control and test samples, respectively.

\section{Reducing power assay}

The reducing power of the obtained extract was determined according to a published method $[5,10]$. Briefly, $0.5 \mathrm{~mL}$ of the untreated and treated sample solution was mixed with $2.5 \mathrm{~mL}$ $0.2 \mathrm{M}$ of phosphate buffer $(\mathrm{pH} 6.6)$ and $2.5 \mathrm{~mL}$ of $1 \% \mathrm{~K}_{3} \mathrm{Fe}(\mathrm{CN})_{6}$. The mixture solution was incubated at $50{ }^{\circ} \mathrm{C}$ and rapidly cooled after 20 min. $2.5 \mathrm{~mL}$ of $10 \%$ TCA was added to the mixture and shaken vigorously, then centrifuged at $3000 \mathrm{rpm}$ for $10 \mathrm{~min}$. $2.5 \mathrm{~mL}$ of supernatant was mixed with $2.5 \mathrm{~mL}$ of $\mathrm{H}_{2} \mathrm{O}$ and $0.5 \mathrm{~mL}$ of 0.1 $\% \mathrm{FeCl}_{3}$, and the absorbance was read at 700 $\mathrm{nm}$ after $10 \mathrm{~min}$. The reagent blank was $80 \%$ of methanol instead of sample solution. Increased absorbance of mixture solution indicated reducing power.

\section{ABTS radical scavenging assay}

Briefly, $5 \mathrm{~mL}$ of ABTS $(7 \mathrm{mM})$ was mixed with 88 $\mu \mathrm{L}$ of potassium persulphate $(2.45 \mathrm{mM})$ and then was allowed to stand for $12 \mathrm{~h}$ in the dark at room temperature. The solution was diluted with phosphate buffered saline $(0.05 \mathrm{M}, \mathrm{pH} 7.4)$ until the absorbance was $0.70 \pm 0.02$ at $734 \mathrm{~nm}$. The solution was stand for $30 \mathrm{~min}$ in the dark before being used. $0.15 \mathrm{~mL}$ of the extract solution was mixed with $2.85 \mathrm{~mL}$ of the solution described above, shaken vigorously, and then left to stand at room temperature for $10 \mathrm{~min}$. The absorbance of the reaction mixture was measured at $734 \mathrm{~nm}$. The control was $80 \%$ of methanol instead of the sample solution. The ABTS radical scavenging capacity of the sample was calculated as in Eq 2.

$$
\text { Inhibition }(\%)=\{(\mathrm{Ac}-\mathrm{As}) / \mathrm{Ac}\} 100
$$

where Ac and As are the absorbance of control and test samples, respectively.

\section{Statistical analysis}

The analysis of variance (ANOVA) was performed by SPSS 11.5 software. $P$ values < 0.05 were regarded as significant and $P$ values $<$ 0.01 as very significant.

\section{RESULTS}

\section{Diagnostic checking of the fitted model}

The regression equation established by model can replace the experimental real point to explain response results. The regression equation was

$$
\begin{aligned}
& Y=4.10886-0.039255 X_{1}+0.15870 X_{2}+ \\
& 0.88624 X_{3}+0.25033 X_{4}+4.06685^{*} 10^{-4} X_{1} X_{2}+ \\
& 5.68694^{*} 10^{-4} X_{1} X_{3}+2.58241^{*} 10^{-4} X_{1} X_{4}+ \\
& 9.92015^{*} 10^{-4} X_{2} X_{3}+3.43468^{*} 10^{-4} X_{2} X_{4}- \\
& 8.30262^{*} 10^{-4} X_{3} X_{4}-1.88227^{*} 10^{-5} X_{1}^{2}-3.10559^{*} 10^{-} \\
& { }^{3} X_{2}^{2}-0.013569 X_{3}^{2}-1.54949^{*} 10^{-3} X_{4}{ }^{2}
\end{aligned}
$$

The Model F-value of 28.26 implies that the model is significant. There is only a $0.01 \%$ chance that a "Model F-Value" this large could occur due to noise. Values of "Prob > F" less than 0.0500 indicate that model terms are significant. In this case $A, B, C, D, B^{\wedge} 2, C^{\wedge} 2$ are significant model terms. Values greater than 0.1000 indicate that the model terms are not significant. If there are many insignificant model terms (not counting those required to support hierarchy), model reduction may improve your model. The "Lack of Fit F-value" of 3.86 implies that there is a $7.45 \%$ chance that a "Lack of Fit F-value" this large could occur due to noise. Lack of fit is bad -- we want the model to fit. This relatively low probability $(<10 \%)$ is troubling.

The "Pred R-Squared" of 0.8172 is in reasonable agreement with the "Adj R-Squared" of 0.9294. This model can be used to navigate the design space.

\section{Interaction between the variables}

The graph of RSM was a 3D response surface plot, which consisting of response values of experimental variables (Fig 1). They can present the interaction between the variables (ethanol concentration, temperature, liquid/solid ratio). 
Table 2: Central composite design arrangement and results

\begin{tabular}{|c|c|c|c|c|c|}
\hline \multirow{3}{*}{ Experiment } & \multicolumn{4}{|c|}{ Coded level } & \multirow{3}{*}{$\begin{array}{c}\text { Total phenolic } \\
\text { yield } \\
\text { (mg/g) } \\
Y\end{array}$} \\
\hline & $\begin{array}{c}\text { Extraction } \\
\text { time } \\
(\min )\end{array}$ & $\begin{array}{c}\text { Ethanol } \\
\text { concentration } \\
(\%)\end{array}$ & Liquid/solid ratio & $\begin{array}{c}\text { Temperature } \\
\left({ }^{\circ} \mathrm{C}\right)\end{array}$ & \\
\hline & $A$ & $B$ & $C$ & $D$ & \\
\hline 1 & $-1(40)$ & $-1(40)$ & $-1(20)$ & $-1(30)$ & 23.682 \\
\hline 2 & $1(120)$ & $-1(40)$ & $-1(20)$ & $-1(30)$ & 24.174 \\
\hline 3 & $-1(40)$ & $1(80)$ & $-1(20)$ & $-1(30)$ & 18.048 \\
\hline 4 & $1(120)$ & $1(80)$ & $-1(20)$ & $-1(30)$ & 18.572 \\
\hline 5 & $-1(40)$ & $-1(40)$ & $1(40)$ & $-1(30)$ & 26.827 \\
\hline 6 & $1(120)$ & $-1(40)$ & $1(40)$ & $-1(30)$ & 26.863 \\
\hline 7 & $-1(40)$ & $1(80)$ & $1(40)$ & $-1(30)$ & 20.832 \\
\hline 8 & $1(120)$ & $1(80)$ & $1(40)$ & $-1(30)$ & 21.520 \\
\hline 9 & $-1(40)$ & $-1(40)$ & $-1(20)$ & $1(70)$ & 28.826 \\
\hline 10 & $1(120)$ & $-1(40)$ & $-1(20)$ & $1(70)$ & 28.957 \\
\hline 11 & $-1(40)$ & $1(80)^{\prime}$ & $-1(20)$ & $1(70)$ & 22.765 \\
\hline 12 & $1(120)$ & $1(80)$ & $-1(20)$ & $1(70)$ & 23.191 \\
\hline 13 & $-1(40)$ & $-1(40)$ & $1(40)$ & $1(70)$ & 30.234 \\
\hline 14 & $1(120)$ & $-1(40)$ & $1(40)$ & $1(70)$ & 30.365 \\
\hline 15 & $-1(40)$ & $1(80)$ & $1(40)$ & $1(70)$ & 23.846 \\
\hline 16 & $1(120)$ & $1(80)$ & $1(40)$ & $1(70)$ & 28.203 \\
\hline 17 & $-1(40)$ & $0(60)$ & $0(30)$ & $0(50)$ & 27.712 \\
\hline 18 & $1(120)$ & $0(60)$ & $0(30)$ & $0(50)$ & 29.645 \\
\hline 19 & $0(80)$ & $-1(40)$ & $0(30)$ & $0(50)$ & 30.201 \\
\hline 20 & $0(80)$ & $1(80)$ & $0(30)$ & $0(50)$ & 24.731 \\
\hline 21 & $0(80)$ & $0(60)$ & $-1(20)$ & $0(50)$ & 25.386 \\
\hline 22 & $0(80)$ & $0(60)$ & $1(40)$ & $0(50)$ & 29.317 \\
\hline 23 & $0(80)$ & $0(60)$ & $0(30)$ & $-1(30)$ & 25.910 \\
\hline 24 & $0(80)$ & $0(60)$ & $0(30)$ & $1(70)$ & 30.267 \\
\hline 25 & $0(80)$ & $0(60)$ & $0(30)$ & $0(50)$ & 28.334 \\
\hline 26 & $0(80)$ & $0(60)$ & $0(30)$ & $0(50)$ & 27.548 \\
\hline 27 & $0(80)$ & $0(60)$ & $0(30)$ & $0(50)$ & 28.039 \\
\hline 28 & $0(80)$ & $0(60)$ & $0(30)$ & $0(50)$ & 27.057 \\
\hline 29 & $0(80)$ & $0(60)$ & $0(30)$ & $0(50)$ & 27.155 \\
\hline 30 & $0(80)$ & $0(60)$ & $0(30)$ & $0(50)$ & 27.155 \\
\hline
\end{tabular}

Table 3: Analysis of mean square deviation of regression equation

\begin{tabular}{cccccc}
\hline Source & $\begin{array}{c}\text { Sum of } \\
\text { Squares }\end{array}$ & df & $\begin{array}{c}\text { Mean } \\
\text { Square }\end{array}$ & $\begin{array}{c}\text { F } \\
\text { Value }\end{array}$ & $\begin{array}{c}\boldsymbol{P} \text {-value } \\
\text { Prob }>\text { F }\end{array}$ \\
\hline Model & 324.4924155 & 14 & 23.17802968 & 28.25601279 & $<0.0001$ \\
A-time & 4.221880133 & 1 & 4.221880133 & 5.1468352 & 0.0385 \\
B-ethanol concentration & 130.2638122 & 1 & 130.2638122 & 158.802797 & $<0.0001$ \\
C-liquid/solid & 33.10131724 & 1 & 33.10131724 & 40.35335427 & $<0.0001$ \\
D-temperature & 89.89636856 & 1 & 89.89636856 & 109.5914094 & $<0.0001$ \\
AB & 1.693621922 & 1 & 1.693621922 & 2.064670869 & 0.1713 \\
AC & 0.827936044 & 1 & 0.827936044 & 1.009325287 & 0.3310 \\
AD & 0.682890395 & 1 & 0.682890395 & 0.832502159 & 0.3760 \\
BC & 0.629819679 & 1 & 0.629819679 & 0.767804388 & 0.3947 \\
BD & 0.302004707 & 1 & 0.302004707 & 0.368169728 & 0.5531 \\
CD & 0.441174478 & 1 & 0.441174478 & 0.537829654 & 0.4746 \\
A^2 & 0.002349923 & 1 & 0.002349923 & 0.002864759 & 0.9580 \\
B^2 & 3.99817144 & 1 & 3.99817144 & 4.874115051 & 0.0433 \\
C^2 & 4.770306704 & 1 & 4.770306704 & 5.815414385 & 0.0292 \\
D $^{\wedge}$ & 0.995292833 & 1 & 0.995292833 & 1.213347614 & 0.2880 \\
Residual & 12.30429954 & 15 & 0.820286636 & & \\
Lack of Fit & 10.8940888 & 10 & 1.08940888 & 3.862574732 & 0.0745 \\
Pure Error & 1.410210747 & 5 & 0.282042149 & & \\
Core Total & 336.7967151 & 29 & & & \\
\hline
\end{tabular}

Fig $1 \mathrm{~A}$ showed that when methanol concentration was at a certain value, the total phenolic yield of wheat bran sample increased with the temperature increased. However, when temperature was unchanged, the total phenolic yield of wheat bran sample declined as the methanol concentration increased. 
It can be seen from Fig 1B that when liquid/solid ratio was at a certain value, the total phenolic yield of wheat bran sample increased with temperature increased. When temperature was unchanged, the total phenolic yield of wheat bran sample rose and then declined slowly with the liquid/solid ratio extended. The best point of balance should be sought for the maximum total phenolic yield of wheat bran sample.
From Fig. 1C, it can be seen that when ethanol concentration was at a certain value, the total phenolic yield of wheat bran sample rose and then declined slowly with the increase of liquid/solid ratio. When the liquid/solid ratio did not vary, the total phenolic yield of wheat bran sample declined with the ethanol concentration extended.

A
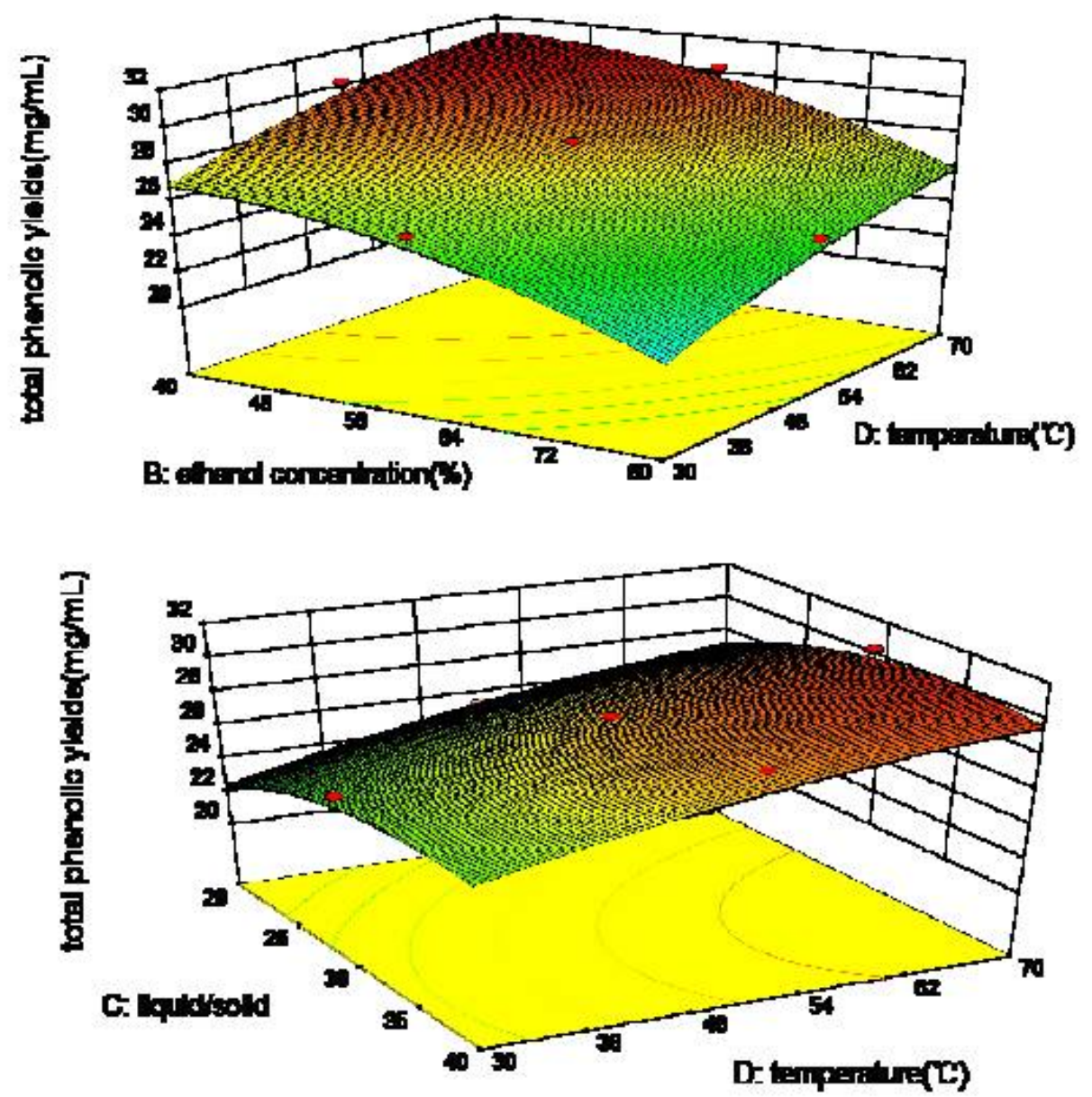

B

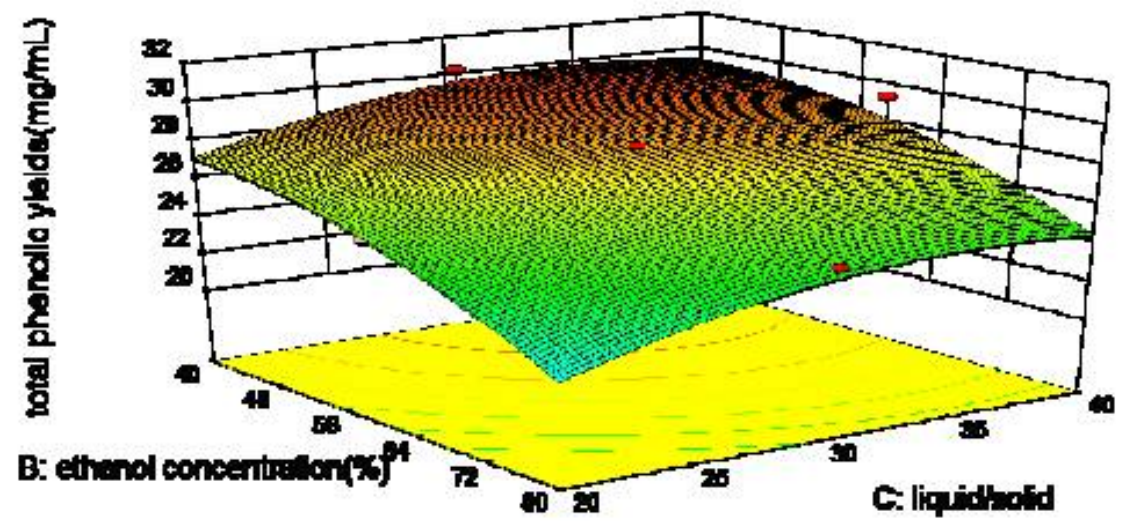

c

Fig 1: Correlative effects of ethanol concentration and temperature (A), liquid/solid and temperature (B), ethanol concentration and liquid/solid (C), on the total phenolic yield 


\section{Optimization of extraction}

The optimum conditions for independent variables and the predicted values of the responses were also presented as follows (Table 4). A verification experiment at the optimum condition, consisting of 3 runs, was performed and the practical yield of $96.14 \pm 0.079 \%$ was obtained.

\section{DPPH radical scavenging activity}

DPPH radical scavenging activities of $\mathrm{BHA}$ and wheat bran sample were shown in Fig. 2, the result showed that the DPPH radical scavenging activities of $\mathrm{BHA}$ had a high and steady trend under the concentration of $0.1-1 \mathrm{mg} / \mathrm{mL}$, the DPPH radical scavenging activities of the wheat bran sample had a trend of increase with the increase of concentration, but still lower than BHA's.

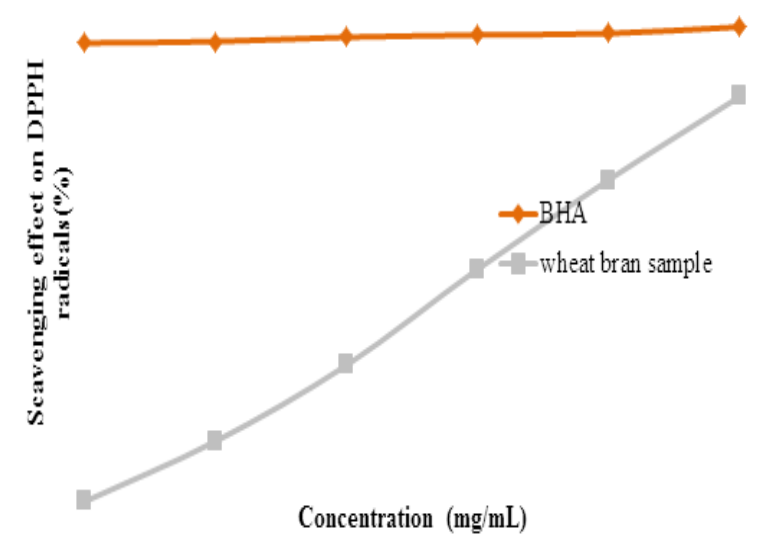

Figure 2: The scavenging effect of wheat bran sample and BHA on DPPH radicals

\section{Reducing power activity}

It is believed that antioxidant activity and reducing power are correlated [8]. The reducing power assays in wheat bran and BHA were shown in Fig. 3. The result showed that the reducing power of $\mathrm{BHA}$ is better than the wheat bran sample. Under the concentration of $2-10$ $\mathrm{mg} / \mathrm{mL}$, the reducing power of $\mathrm{BHA}$ remained high and steady trend. The reducing power of wheat bran extracts increased with the increase

Table 4: Experimental verification outcome of the concentration, when the concentration reached $10 \mathrm{mg} / \mathrm{mL}$, the reducing power of wheat bran extracts was nearly half of BHA's.

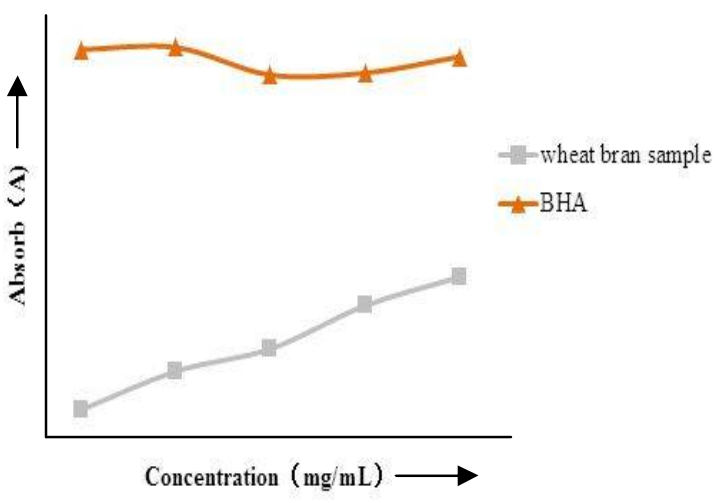

Figure 3: The reducing power activity of wheat bran sample and BHA

\section{ABTS radical scavenging activity}

The ABTS radical scavenging assays were shown in Fig. 4. The result showed that the BHA had a high scavenging capacity with a slight decrease under the concentration of $2-10$ $\mathrm{mg} / \mathrm{mL}$. When the concentration ranged from 2 to $6 \mathrm{mg} / \mathrm{mL}$, the scavenging capacity of wheat bran sample significantly increased, which was lower than that of BHA. When the concentration reached $6 \mathrm{mg} / \mathrm{mL}$, the $B H A$ and wheat bran sample had the similar high scavenging capacity, after $6 \mathrm{mg} / \mathrm{mL}$, the ABTS radical scavenging of wheat bran was better than BHA's.

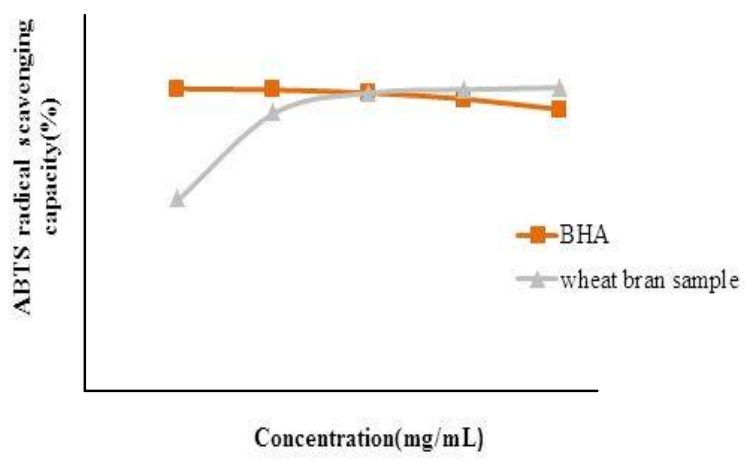

Figure 4: The ABTS radical scavenging capacity of wheat bran sample and BHA

\begin{tabular}{lccccc}
\hline Variable & $\begin{array}{c}\text { Extraction time } \\
(\mathbf{s})\end{array}$ & $\begin{array}{c}\text { Ethanol content } \\
(\%)\end{array}$ & $\begin{array}{c}\text { Liquid/solid } \\
(1: 1)\end{array}$ & $\begin{array}{c}\text { Temperature } \\
\left({ }^{\circ} \mathbf{C}\right)\end{array}$ & $\begin{array}{c}\text { Total phenolic } \\
\text { yield }(\%)\end{array}$ \\
\hline Predict & 120 & 42.66 & $34.56: 1$ & 70 & 31.687 \\
Experiment & 120 & 43 & $35: 1$ & 70 & $30.464 \pm 0.025$ \\
\hline
\end{tabular}




\section{CONCLUSION}

Phenolic acids are rich in the wheat bran; the treatment of steam explosion is a good way to release the phenolic acids in the wheat bran. The optimum conditions of extraction as determined by response surface methodology are as follows: extraction time: $120 \mathrm{~s}$, ethanol content: $43 \%$, liquid/solid: $35: 1$, temperature: $70{ }^{\circ} \mathrm{C}$. The findings of this work indicate that although the reducing capacity of wheat bran sample is lower than BHA in a certain concentration range, the $\mathrm{DPPH}$ radical scavenging activity and ABTS radical scavenging capacity of wheat bran sample is similar to those of BHA at certain concentrations, and that extraction of wheat bran under steam explosion is a suitable approach for obtaining a high yield of natural antioxidants.

\section{ACKNOWLEDGEMENT}

This work was supported by Special Fund for the Construction of Wheat Technology System in Henan Province (no. S2010-01-G06), Research Foundation for Advanced Talents (no. 2011BS005), Research Foundation of HAUT (no. 2013JCYJ01) and Program for Innovative Research Team in University of Henan Province (no. 13IRTSTHN008).

\section{REFERENCES}

1. Zheng $X L$, Yao HY, Li LM, Zhang XD. The Utilization of Wheat Bran-the By-product of Flour Milling. Food Feed Ind 2001; 12: 38-39.
2. $X u G H, Y e X Q$. Effect of Heat Treatment on the Phenolic Compounds and Antioxidant Capacity of Citrus Peel Extract. J Agr Food Chem 2007; 55: 330-335.

3. Yu LL. Wheat Antioxidants. United States of America: John Wiley \& Sons, Inc., Hoboken, New Jersey, 2007;236-238

4. Sun T, Ho CT. Antioxidant activities of buckwheat extracts. Food Chemistry 2005; 90: 743-749.

5. Joseph GS, Jayaprakasha GK, Selvi AT, Jena BS, Sakariah KK. Antiaflatoxigenic and antioxidant activities of Garcinia extracts. Int J Food Microbiology 2005; 101 : 153-160.

6. Liu BG, Ma YX, Liu Y, Yang Z, Zhang LP, UltrasonicAssisted Extraction and Antioxidant Activity of Flavonoids from Adinandra nitida Leaves. Trop J Pharm Res 2013; 12(6): 1045-1051.

7. Yuan XH, Fu LN, Gu CB, Zhang YD, Fu YJ. Microwaveassisted extraction and antioxidant activity of vaccarin from the seeds of Vaccaria segetalis. Sep Purif Technol 2014; 133: 91-98.

8. Meir S, Kanner J, Akiri B, Hadas SP. Determination and involvement of aqueous reducing compounds in oxidative defense systems of various senescing leaves. J Agr Food Chem 1995; 43: 1813-1815.

9. Mu YD. Response Surface Methodology and its Application in Food Industry. J Zhengzhou Inst Tech 2001; 22(3); 91-94.

10. Zhu KX, Lian $C X$, Guo $X N$, Peng $W$, Zhou $H M$. Antioxidant activities and total phenolic contents of various extracts from defatted wheat germ. Food Chem 2011; 126: 1122-1126.

11. Gong $L X$, Huang LL, Zhang Y. Effect of Steam Explosion Treatment on Barley Bran Phenolic Compounds and Antioxidant Capacity. J Agr Food Chem 2012; 60: $7177-$ 7184. 